\title{
Intraductal and Lobular Carcinoma
}

National Cancer Institute

\section{Source}

National Cancer Institute. Intraductal and Lobular Carcinoma. NCI Thesaurus. Code C7690.

A breast carcinoma characterized by the presence of a ductal carcinoma in situ component and an in situ or invasive lobular carcinomatous component. 